\title{
Insect "Bee\&Bees" and pollinator penthouses: teaching students about pollinators and their services in an urban environment
}

\author{
Elizabeth N. Hane $^{1}$ (D) Karl F. Korfmacher $^{1}$
}

Accepted: 10 November 2021 / Published online: 16 February 2022

(c) The Author(s) 2022

\begin{abstract}
Pollination services are a frequently overlooked component of urban ecosystems. As cities look to become more sustainable and incorporate more urban green spaces, these pollinator services are coming to the forefront, and educating the public about the habitat and foraging needs of urban pollinators is becoming more important. Increasingly popular features in urban gardens are "bug hotels", which are artificial structures that humans can install to create habitat or shelter for urban insect pollinators. In a college-level Urban Ecology class, we use a structured classroom activity to teach students about pollinator needs, but also place the activity in a larger context of a discussion about the value of urban landscapes, as well as the importance of evaluating sources of information. Here we describe the steps of a research activity that students undertake to design a "bug hotel", as well as suggestions for how to extend the activity beyond the classroom.
\end{abstract}

Keywords Active learning $\cdot$ Urban ecology $\cdot$ Ecosystem services $\cdot$ Pollinator services $\cdot$ Bug hotels

\section{Introduction}

When asked to imagine a pollinator, most people probably picture a honey bee buzzing from flower to flower. However, a wide variety of insects, birds, and mammals pollinate both natural and cultivated plants. Pollination, which falls into the "supporting" category of ecosystem services, provides essential functions for many plants that rely on animals for dispersal of their pollen (Elmqvist et al. 2015). Pollinators are also important drivers of the biodiversity of ecosystems, as their presence is essential for the genetic flow that establishes future generations of flowering plants. Habitats for pollinators may be degraded or non-existent in urban settings, and may need to be augmented in order to support effective population sizes for pollinator services. As cities recognize the importance of sustainable and biodiverse green spaces within the urban landscape, these services become more important, particularly when planning urban parks and gardens (USEPA 2015). Additionally, urban agriculture is becoming increasingly popular in various forms (e.g. community gardens) (USEPA 2015; Bennett and Lovell

Elizabeth N. Hane

enhsbi@rit.edu

1 Gosnell School of Life Sciences, Rochester Institute of Technology, Rochester, NY, USA
2019), and a large proportion of plants grown in urban gardens are dependent on bee pollinators to set fruit (Matteson and Langellotto 2009).

Declines in insect pollinator populations have been documented worldwide, including urban areas (Potts et al. 2010; Burkle et al. 2013; Vanbergen et al. 2013; Soroye et al. 2020). In North America, native bee populations are in decline due to introduced pathogens (e.g. Nosema bombi) and low genetic diversity due to habitat fragmentation and destruction (Cameron et al. 2011). Further cause for declines includes populations of non-native European honeybees (Apis mellifera), which are out-competing native bees, pushing them out of their native habitats (Thompson 2016). Thus, finding ways to support native bees and other insect pollinators is important for preservation of biodiversity (Lowenstein et al. 2015) and to support pollination services, including habitat restoration and/or augmentation.

Urban areas often are thought of as ecological deserts with low biodiversity. However, people living in urban areas are dependent on local biodiversity due to its generation of ecosystem services, such as pollination, but are often unaware of the importance of these services or how they might be occurring in urban areas. Raising awareness about the importance of these services through education and restoration efforts is an opportunity to both connect people to the 
natural environment and also support the native pollinator populations (Matteson et al. 2008; Theodorou et al. 2020).

Urban gardens and other green spaces may provide food resources for native bees and other insect pollinators, particularly as the popularity of urban agriculture and "pollinator gardens" are increasing (Paweleck et al. 2009; USEPA 2015; Bennett and Lovell 2019). However, while conservation efforts often focus on floral resource provisioning, bee communities are also dependent on availability of diverse nesting resources (Potts et al. 2003). Many pollinators also have specific shelter or nesting requirements that are more difficult to meet in an urban setting, particularly for species that require deadwood, leaf litter, or other natural materials (Fortel et al. 2016). For instance, fallen wood and leaves are often removed in urban landscapes for aesthetic reasons, eliminating potential habitat for insects of all kinds (Steffan-Dewenter and Leschke 2003; McFrederick and LeBuhn 2006). Urbanization also degrades habitat for ground-nesting species by altering vegetation and increasing both soil compaction and impervious cover (Cane et al. 2006; Geslin et al. 2016; Bennett and Lovell 2019). On a landscape scale, bee biodiversity has been found to be negatively correlated with urban development (Dauber et al. 2003) and impervious surfaces (Arhné et al. 2009). An analysis of 59 urban bee surveys found that urban areas tended to have lower diversity and abundance of bee species, particularly for ground nesters and floral specialists (Hernandez et al. 2009).

One increasingly popular way to counteract this pattern of habitat removal is to create "bug hotels" and install them in urban gardens or natural areas, where they can be used by native insects for shelter (or as the title suggests, as a "bee\&bee" or pollinator penthouse) (Gaston and Smith 2005) (Figs. 1 and 2). Depending on the design and materials used, the bug hotels can be targeted to specific taxa of pollinators (Fortel et al. 2016). While they are often referred to by the public as "bug hotels," the shelters often cater to native bee populations (Table 1), rather than true bugs (Order: hymenoptera). However, these bug hotels can also be designed to provide habitat for other types of insects, such as predatory ladybugs (there are over 500 species in North America) and green lacewings, thus enhancing biodiversity as well as promoting pollination and other ecosystem services. They may be thought of more generally as artificial habitats for desirable pollinators and bio-control insects.

The efficacy of bug hotels is still being evaluated (MacIvor and Packer 2015; Geslin et al. 2020), particularly for hotels that are designed more generally rather than for a targeted taxon. Recent research in Europe indicates that some urban bug hotels may draw in more exotic species (e.g. Megachile sculpturalis) than native bees (Geslin et al. 2020; Ruzzier et al. 2020),
Fig. 1 Examples of bug hotels from public gardens around southern Sweden. The examples range from very complex (see A-which not only has a wide variety of materials, but also has a sedum green roof) to quite simple (see C-just bamboo in a frame). Examples $\mathrm{C}$ and $\mathrm{E}$ are mounted on walls or posts, while A, B and D are free standing. Photos by E. Hane and K. Korfmacher
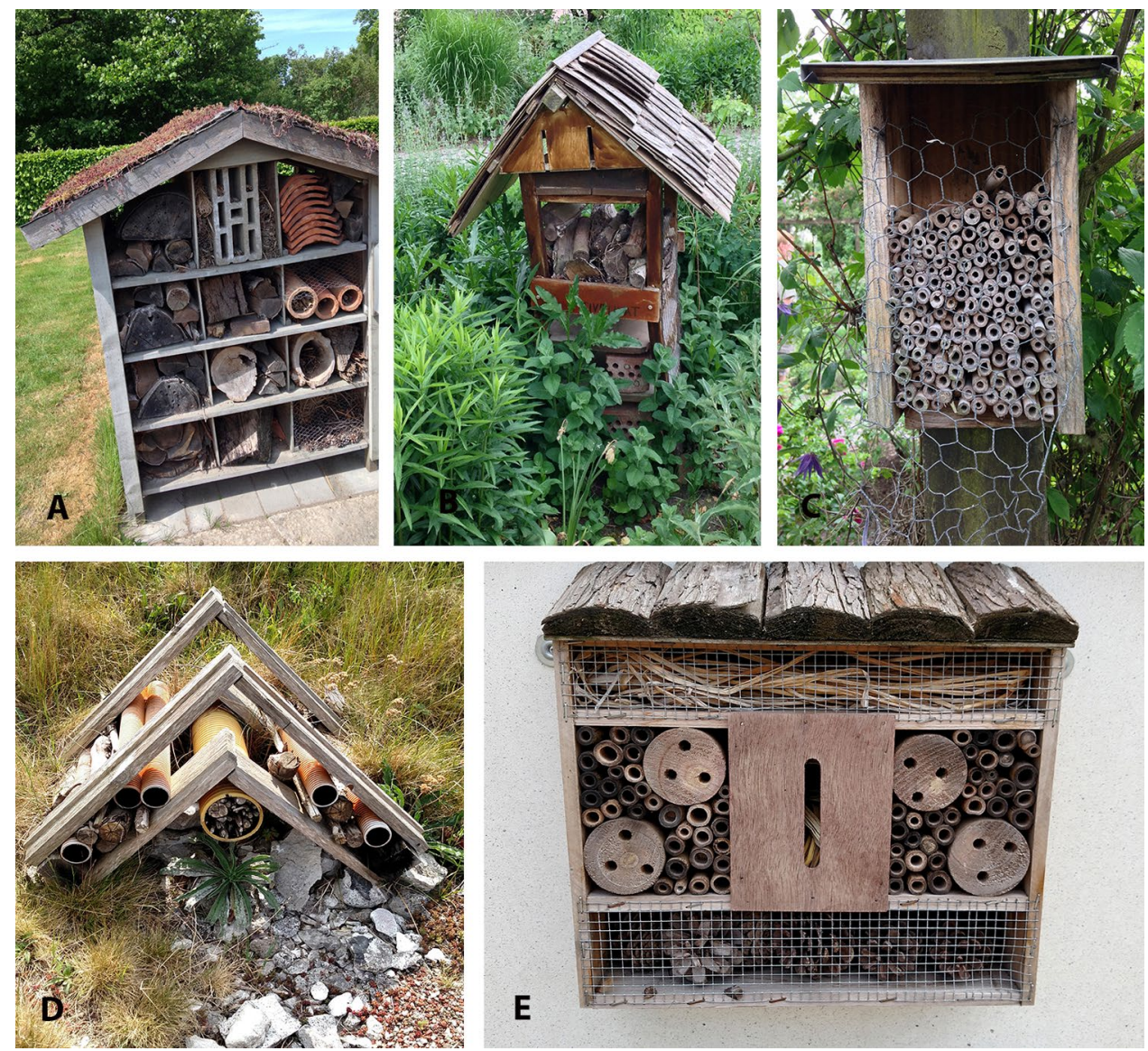


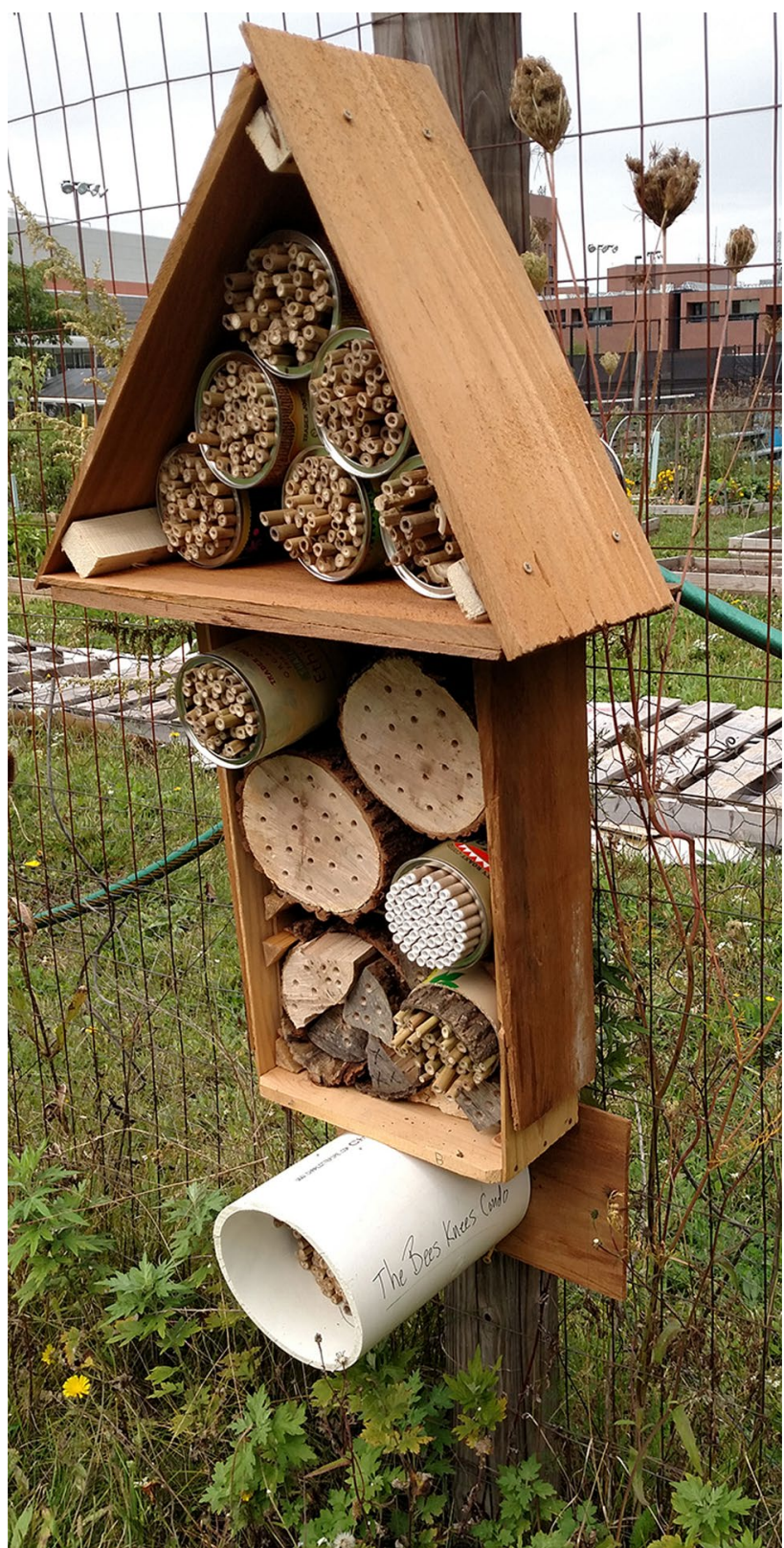

Fig. 2 An example of a bug hotel that was built by students in RIT's Urban Ecology class in the spring of 2019. It has been permanently installed on the fence surrounding the RIT Community Garden. Photo by K. Korfmacher

though this is thought to be potentially less of an issue in North America (Stevens et al. 2019). In a classroom setting, this can provide an important avenue for discussion about how one evaluates the success of habitat augmentation or restoration, and what the goals of such efforts should be. As part of a course on urban ecology (course details in Hane and Korfmacher 2020), we designed an activity, described below, that asks students to design their own bug hotel for an urban setting, including both the design as well as a written report that describes the design, materials, targeted taxa, and the rationale for why the student made those choices. The activity requires that students identify native pollinators in their area, learn about their habitat needs, and think creatively about solutions. It also involves them in the process of finding reliable sources and evaluating evidence that may support their proposed solutions.

\section{Learning outcomes}

After completing this activity, students should be able to:

- Identify both global and local threats to insect pollinators

- Describe the ecosystem services that insects provide in urban landscapes

- Discuss the ecological needs of insect pollinators and how those could be met within an urban area, with particular attention to local, native species

- Discuss how humans modify and impact the urban environment in ways that impact insect pollinators

- Describe pros and cons of creating artificial habitat ("bug hotels") for pollinators and other beneficial insects as a way to enhance urban biodiversity

- Identify a desirable pollinator insect taxonomic group and design habitat enhancement ("bug hotel") for that group that can be used in an urban environment

- Evaluate sources of evidence for reliability

\section{Course context}

- Originally designed as an active learning exercise and homework assignment in an Urban Ecology course for $10-16$ students, with a mix of $2^{\text {nd }}$ year undergraduates to graduate students from a variety of majors

- 50 min of instruction time in one class setting, with optional second class period if building the insect hotels is desirable/feasible

- Design by students is done as homework, or could be done in class if additional time is available

- Some background knowledge of ecosystem services is helpful (our class has a previous session and activity devoted to this topic. See Hane and Korfmacher (2021))

- Adaptable to classes of any size

\section{Instructor preparation and materials}

To carry out this activity, the instructor will need to provide a 20-30 min overview on ecosystem services focused on pollinator services, to (A) describe what they are and why they are important, (B) describe the threats and challenges to insect pollinator populations, particularly in urban environments, and (C) lead a discussion of what might be done to improve habitat 
Table 1 Examples of common bee taxa native to the northeastern United States that could be incorporated into designs for artificial insect habitats. This information was derived from the Ohio Bee Identification Guide (Prajzner and Gardiner 2021), produced by the Ohio
State University Extension Service. The guide includes photographs, behavior cues and other information for identifying bees. Instructors may need to generate a table for their own geographical region

\begin{tabular}{lll}
\hline Nesting Type & Associated Bee groups (Genera) & Suggested materials \\
\hline Ground & Mining bees (Andrena) & Bare patches of dry soil, often south-facing \\
& Cellophane bees (Colletes) & \\
Wood & Carpenter (Xylocopa) & Natural, untreated wood \\
Cavity & Bumble bees (Bombus) & Existing cavities in ground (often old \\
& & rodent holes) or large holes in other \\
& & materials \\
Tunnel & Carpenter (Ceratina) & Twigs, untreated bamboo, hollow stems \\
& Mason (Osmia) & \\
\hline
\end{tabular}

for various types of insect pollinators, including introducing the idea of bug hotels, with examples, if desired. We have provided an example set of slides (with notes) that introduces ecosystem services, pollinator services, threats to pollinators in urban areas, and bug hotel examples (Supplementary Material 1). These slides can be edited to match the goals and level of an individual class. The instructor should decide, depending on the level of the students, how much to lead the students into particular bug hotel designs or materials by using specific examples. Beginning students may need more direction and examples, while more advanced students could be left to do this research and discovery on their own. This overview could be done in a classroom space or a suitable open space on campus (e.g. community garden, butterfly garden, or planting area). If desirable, the instructor should identify a nearby park, green space or natural area that could be a target for hotel installation. Resources for information about pollinators are listed in supplementary material 2 , but the instructor may wish to conduct their own search for and evaluation of internet sources about building bug hotels for their geographical region and incorporate them into a modified version of this handout for students. In the United States, an excellent place to start is with state and local agricultural extension offices, which often have publications about local bee ecology (see examples: NAPPC and Pollinator Partnership (2013); Brokaw and Isaacs 2017; Prajzner and Gardiner 2021).

The second step, building a bug hotel as a class, is optional for this activity. If time allows, the instructor could use part of a class period to discuss the pros and cons of various designs that were turned in, or alternatively, have students critique each other's designs. As part of this process, students and the instructor could work together to choose a student submitted design for the class to build. A second class day should be set aside for this activity, preferably in a laboratory or space where tools can be accessed easily. Our recommendation is to choose something relatively simple and for which the materials can be gathered easily. For example, locally sourcing bamboo stakes that have not been treated with chemicals is surprisingly difficult to do, especially in winter or early spring when many garden centers have not yet opened (or received their gardening shipments). Materials may need to be ordered and shipped (such as paper mason bee tubes), so plan ahead. Depending on class size, bringing in additional help (perhaps from facilities staff) may be desirable at this stage. It should be noted that you can purchase various bug hotel kits, which may also be helpful for sourcing pre-cut or partially assembled hotels. While the hotels may be built at any time of the year, they are more likely to be used if they are deployed into the field in spring as the growing season is beginning. Though it requires more time and resources, in our experience, actually building a hotel is worthwhile because students enjoy seeing their work turned into a physical object which helps make the lesson more tangible and impactful.

\section{Learning activities}

The flow of activities is as follows:

- Introduce pollinators and lead discussion about habitat needs and what humans can do to support insect pollinators in an urban environment (20 min)

- Introduce the concept of bug hotels (5 min)

- Describe and hand out homework assignment details (Box 1; 5 min)

- Discuss internet sources and how to find reliable information (10 min)

- Identify locations on campus or in nearby urban area that should be targeted for hotel installation (10 min)

After the introduction, the instructor should explain the assignment (Box 1). This is a good time to discuss internet sources and their reliability. The instructor should explain that there are many examples of bug hotels available on the internet, but not all of them are equally effective at supporting insect populations. Students often have a difficult time distinguishing reliable 
sources from unreliable ones. Discussion could focus on: 1) Who is an expert for this topic and how do you know? 2) What peerreviewed information is available and how do we find it? 3) How do we resolve conflicting information? 4) Should you trust kits sold at home improvement and garden centers or build your own?

If desired, the instructor could identify a specific area of campus or a local park/natural area that should be targeted for the installation of a bug hotel or the instructor could lead the students in a discussion about where they think the hotel should be located, focusing on: 1) what do specific pollinators need and how does this location meet those needs, 2) if there are needs missing, would a bug hotel help meet those needs, and 3) are there threats (e.g. pesticide applications, mowing, etc.) to insects in this area that make it less suitable?

\section{Box 1:}

\section{Example of homework assignment:}

One method of increasing native diversity in urban areas is to create habitat for desirable species. A popular choice is to build a "bug hotel" (or "bee\&bee" or pollinator penthouse) out of various materials and put it near a garden or park in order to increase desirable insect (typically native bee) populations.

Your task requires two steps. The first step is to design a bug hotel, including a rationale of why you designed it that way and what materials you picked and why. The second step is to build an example or two of the submissions from the class at a later date (depending on the weather).

\section{Your design (what you turn in!) should include the following components:}

1) Information about what species you are trying to attract and why you chose them

2) List of materials needed to build your bug hotel

3) Descriptions, pictures, drawings, instructions, or other visuals of your design

4) Description of why you picked those materials and that design. What habitat needs does your design fill? Include citations to indicate where your information came from and a reference list.

You will find that there is a plethora of information out on the web (not all of it actually useful) about how to create a bug hotel. Here's a few to get you started:

$<$ Insert instructor choices for good sources of information. We have included what we use in Supplement 2> $<$ end box $>$

\section{Extensions and additional connections}

There are additional activities or topics that could be added or extended, depending on the emphasis and learning outcomes of the course. One of our main goals was to have students evaluate information that they found on the internet, but these extensions could be adjusted to meet other goals, such as working in groups, advanced content, etc. Here are a few suggestions:

- Hold a second session on the bug hotels in a lab space and allow the students to build one or two of the designs during the class period. You could choose the designs based on simplicity, available materials, or popular vote.

- If hotels are installed, this assignment can be linked to other courses, such as ecology or environmental science/ studies courses, where students can monitor the installations and evaluate which designs and materials work best, inventory the diversity of the insect guests, etc. What insects use the habitat? Are they desirable? What modifications might need to be made to the habitat if the hotel is attracting undesirable inhabitants?

- Have students write a short reflective piece at the end of the lesson that ties it to the larger course objectives. Why are pollinators important in an urban environment? How do they contribute to the sustainability or ecosystem services of an urban area?

- Encourage students to explore the impacts of enhancing insect biodiversity on other taxonomic groups and ecosystem services. This can lead to a discussion of ecosystem enhancements that have multiple benefits (see Hane and Korfmacher 2021).

- Have students think about a simple, inexpensive design that could be shared with and built by the public, especially children at a local festival, Earth Day celebration, or other public event.

- Have students explore the process of getting permission to have a bug hotel installed on campus. Who needs to be involved, and what issues may come up? This may be a good place to discuss the potential that people will object to having a bug hotel on campus based on fear surrounding stinging, potentially in people with serious allergies. The concept of ecosystem disservices (negative impacts of nature on humans or human health) could be explored more here in an advanced class (See Larson et al. 2019).

- Ask students to think about the public spaces in their hometown or in a nearby city. Are there opportunities for engaging the public to build insect hotels in that area? Which local groups might be interested in contributing (e.g., garden clubs, youth organizations, schools, science centers)? 


\section{Reflections and conclusions}

Student designs for bug hotels are often creative and fun, but may lack a more rigorous examination of why certain designs or materials were chosen. Students also often have a difficult time distinguishing good from bad advice about what materials to use and determining what a reliable source of information is. For example, one source may encourage the use of pinecones as a natural substance in the bug hotel (Royal Society for the Protection of Birds 2020), while another source discourages it due to the undesirability of the insect taxa that the pinecones attract (Teh-Weisenburger 2017). We are now able to evaluate designs and materials after having student projects out in the environment for over a year to see what is working and what is not. Surveys of the bamboo tubes and drilled holes at the end of the season revealed that $30 \%$ had been utilized, with approximately $20 \%$ used by mason bees (Osmia sp.) and 10\% used by grass-carrying wasps (Isodontia sp.) (Fig. 3; E. Hane and K. Korfmacher, unpublished data). Isodontia are an important native pollinator, particularly in grasslands and gardens

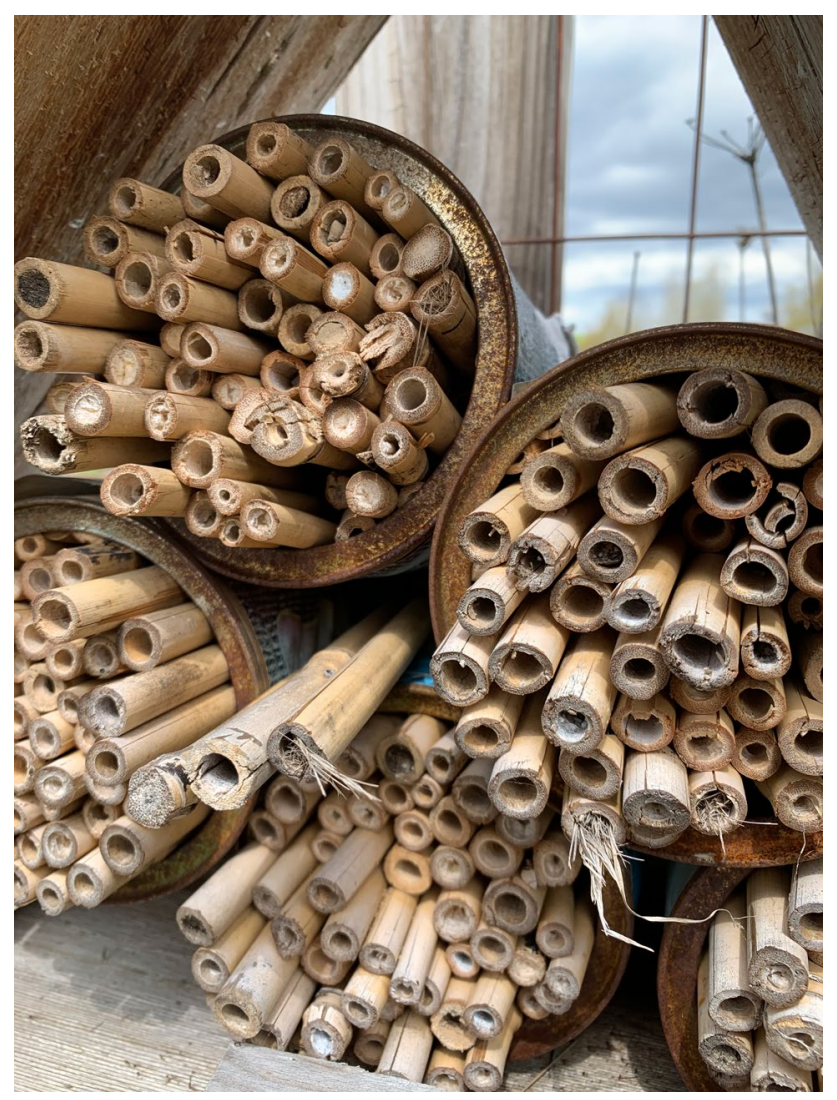

Fig. 3 Bug hotel from the class project, showing the bamboo with pollinator nests at the end of the growing season. The bamboo has been colonized by mason bees (Osmia sp.) and grass-carrying wasps (Isodontia), both native species and important garden pollinators. Photo by E. Hane
(Holm 2016; Brown 2017). Such information can help future classes critically think about the challenges of mimicking nature.

Students from various backgrounds may approach the problem from their own perspectives and expertise. Environmental science students tend to focus on the biology and habitat needs of specific species. Engineering students often approach the problem looking for technical solutions (e.g. materials or structural design). Art and design students tend to focus more on aesthetics (e.g. drawings, plans, textures, etc.). Integrating these perspectives is one of the learning outcomes of our Urban Ecology course, and thus having opportunities for the students to work together helps students achieve that outcome (Hane and Korfmacher 2020, 2021). A similar communication outcome can be achieved by engaging students in environmental outreach though the development of signage and participating in or hosting public workshops. For example, we have successfully engaged our classes in outreach activities at the annual Imagine RIT festival (https://www.rit.edu/imagine/).

Our assessment of the students' work shows that they enjoy the creativity involved in this assignment, but struggle with documenting the reasons behind their decisions. Thinking about a particular taxonomic group and focusing on the habitat needs of that group help direct the students to questions of biology. Participation in a larger conversation about where and how to place the insect hotel helps place the biology in the larger context of ecosystem services and the urban environment. Further, the activity could be a catalyst for encouraging students to modify their own urban spaces (or to be a part of a group that does this) to restore habitats for increased pollinator abundance and diversity.

Supplementary Information The online version contains supplementary material available at https://doi.org/10.1007/s11252-021-01186-4.

Acknowledgements We would like to thank RIT Facilities Management (Building and Grounds) and Enid Cardinal, RIT Senior Advisor to the President for Strategic Planning and Sustainability. Funding for the activity came from a RIT Provost Learning Initiation Grant. The paper was significantly improved by the contributions of four anonymous reviewers and a very diligent editor.

Funding Funding provided by an internal grant from the Provost's Office at Rochester Institute of Technology.

Data availability N/A

Code availability N/A

\section{Declarations}

Ethics approval N/A

Consent to participate N/A 


\section{Consent for publication N/A}

\section{Conflicts of interest None}

Open Access This article is licensed under a Creative Commons Attribution 4.0 International License, which permits use, sharing, adaptation, distribution and reproduction in any medium or format, as long as you give appropriate credit to the original author(s) and the source, provide a link to the Creative Commons licence, and indicate if changes were made. The images or other third party material in this article are included in the article's Creative Commons licence, unless indicated otherwise in a credit line to the material. If material is not included in the article's Creative Commons licence and your intended use is not permitted by statutory regulation or exceeds the permitted use, you will need to obtain permission directly from the copyright holder. To view a copy of this licence, visit http://creativecommons.org/licenses/by/4.0/.

\section{References}

Ahrné K, Bengtsson J, Elmqvist T (2009) Bumble Bees (Bombus spp) along a Gradient of Increasing Urbanization. PLoS One 4(5):e5574. https://doi.org/10.1371/journal.pone.0005574

Bennett AB, Lovell S (2019) Landscape and local site variables differentially influence pollinators and pollination services in urban agricultural sites. PLoS One 14(2):e0212034. https://doi.org/10. 1371/journal.pone.0212034

Brokaw J, Isaacs S (2017) Building and managing bee hotels for wild bees. Michigan State University Extension. Extension Bulletin E-3337. https://pollinators.msu.edu/publications/building-andmanaging-bee-hotels-for-wild-bees/. Retrieved 22 April 2021

Brown D (2017) The grass-carrying wasp: A solitary wasp that builds nests in unusual places. Michigan State University Extension Service. https://www.canr.msu.edu/news/the_grass_carrying_ wasp_a_solitary_wasp_that_builds_nests_in_unusual_places. Accessed 17 May 2021

Burkle LA, Marlin JC, Knight TM (2013) Plant-pollinator interactions over 120 years: loss of species, co-occurrence, and function. Science 339:1611-1615. https://doi.org/10.1126/science.1232728

Cameron SA, Lozier JD, Strange JP, Koch JB, Cordes N, Solter LF, Griswold TL (2011) Patterns of widespread decline in North American bumble bees. PNAS 108(2):662-667. https://doi.org/ 10.1073/pnas. 1014743108

Cane JH, Minckley RL, Kervin LJ et al (2006) Complex responses within a desert bee guild (Hymenoptera: Apiformes) to urban habitat fragmentation. Ecol Appl 16:632-644. https://doi.org/10. 1890/1051-0761(2006)016[0632:CRWADB]2.0.CO;2

Dauber J, Hirsch M, Simmering D, Waldhardt R, Otte A, Wolters V (2003) Landscape structure as an indicator of biodiversity: matrix effects on species richness. Agr Ecosyst Environ 98:321-329

Elmqvist T, Setälä H, Handel SN, van der Ploeg S, Aronson J, Blignaut J, Gomez-Baggethun E, Nowak D, Kronenburg J, de Groot R (2015) Benefits of restoring ecosystem services in urban areas. Current Opinion in Environmental Sustainability 14:101-108. https://doi. org/10.1016/j.cosust.2015.05.001

Fortel L, Henry M, Guilbaud L, Mouret H, Vaissière BE (2016) Use of human-made nesting structures by wild bees in an urban environment. J Insect Conserv 20:239-253. https://doi.org/10.1007/ s10841-016-9857-y

Gaston KJ, Smith RM, Thompson K, Warren PH (2005) Urban domestic gardens (II): Experimental tests of methods for increasing biodiversity. Biodivers Conservation 14:395-413. https://doi.org/10. 1007/s10531-004-6066-x
Geslin B, Le Feon V, Folschweiller M, Flacher F, Carmignac D, Motard E et al (2016) The proportion of impervious surfaces at the landscape scale structures wild bee assemblages in a densely populated region. Ecol Evol 6(18):6599-6615. https://doi.org/10.1002/ece3. 2374

Geslin B, Gachet S, Deschamps-Cottin M, Flacher F, Ignace B, Knoploch C, Meineri E, Robles C, Ropars L, Schurr L, Le Féon V (2020) Bee hotels host a high abundance of exotic bees in an urban context. Acta Oecologica 105:103556. https://doi.org/10.1016/j.actao.2020. 103556

Holm E (2016) Meet the grass-carrying wasp, a gentle pollinator of summer flowers. https://www.houzz.com/magazine/meet-thegrass-carrying-wasp-a-gentle-pollinator-of-summer-flowersstsetivw-vs 58817932. Accessed 17 May 2021

Hane E, Korfmacher K (2020) Integrating multiple perspectives in an urban ecology course. Landscape Online 82:1-14. https://doi.org/ 10.3097/LO.202082

Hane EN, Korfmacher KF (2021) Engaging students in redesigning a local urban space to improve ecosystem services. Urban Ecosyst. https://doi.org/10.1007/s11252-021-01184-6

Hernandez JL, Frankie GW, Thorp RW (2009). Ecology of Urban Bees: a review of current knowledge and directions for future study. Cities and the Environment (CATE): 2(1) Article 3. https:// digitalcommons.lmu.edu/cate/vol2/iss $1 / 3$

Larson K, Corley E, Andrade R, Hall SJ, York A, Meerow S, Coseo P, Childers DL, Hondula D (2019) Subjective evaluations of ecosystem services and disservices: an approach to creating and analyzing robust survey scales. Ecol Soc 24(2):7. https://doi.org/10. 5751/ES-10888-240207

Lowenstein DM, Matteson KC, Minor ES (2015) Diversity of wild bees supports pollination services in an urbanized landscape. Oecologia 179(3):811-821. https://doi.org/10.1007/s00442-015-3389-0

MacIvor JS, Packer L (2015) 'Bee Hotels' as tools for native pollinator conservation: a premature verdict? PLoS One 10(3):e0122126. https://doi.org/10.1371/journal.pone.0122126

Matteson KC, Ascher JS, Langellotto GA (2008) Bee richness and abundance in New York City urban gardens. Ann Entomol Soc Am 101(1):140-150. https://doi.org/10.1603/0013-8746(2008) 101[140:BRAAIN]2.0.CO;2

Matteson KC, Langellotto GA (2009) Bumble Bee abundance in New York City community gardens: implications for urban agriculture. Cities and the Environment 2:1:5. https://digitalcommons.lmu. edu/cate/vol2/iss $1 / 5 /$

McFrederick QS, LeBuhn G (2006) Are urban parks refuges for bumble bees Bombus spp. (Hymenoptera: Apidae)? Biol Conserv 129:372-382. https://doi.org/10.1016/j.biocon.2005.11.004

NAPPC and Pollinator Partnership (2013) Selecting plants for pollinators: a regional guide for farmers, land managers, and gardeners in the eastern broadleaf forest continental province. https://www. pollinator.org/PDFs/Guides/EBFContinentalrx13FINAL.pdf. Accessed 18 May 2020

Pawelek J, Frankie GW, Thorp RW, Przybylski M (2009) Modification of a community garden to attract native bee pollinators in urban San Luis Obispo, California. Cities and the Environment 2:1:7. https://digitalcommons.lmu.edu/cate/vol2/iss1/7

Potts SG, Vulliamy B, Dafni A et al (2003) Linking bees and flowers: how do floral communities structure pollinator communities? Ecology 84:2628-2642. https://doi.org/10.1890/02-0136

Potts SG, Biesmeijer JC, Kremen C, Neumann P, Schweiger O, Kunin WE (2010) Global pollinator declines: Trends, impacts and drivers. TREE 25:345-353. https://doi.org/10.1016/j.tree.2010.01.007

Prajzner S, Gardiner M (2021) Ohio Bee Identification Guide. Ohio State University Extension Service Publication ENT-57. https:// ohioline.osu.edu/factsheet/ENT-57. Retrieved 22 April 2021 
Royal Society for the Protection of Birds (2020) Build a Bug Hotel. https://www.rspb.org.uk/get-involved/activities/give-naturea-home-in-your-garden/garden-activities/build-a-bug-hotel/. Accessed 1 June 2020

Ruzzier E, Menchetti M, Bortolotti L, Selis M, Monterastelli E, Forbicioni L (2020) Updated distribution of the invasive $\mathrm{Meg}$ achile sculpturalis (Hymenoptera: Megachilidae) in Italy and its first record on a Mediterranean island. Biodivers Data J 8:e57783. https://doi.org/10.3897/BDJ.8.e57783

Soroye P, Newbold T, Kerr J (2020) Climate change contributes to widespread declines among bumble bees across continents. Science 367(6478):685-688. https://doi.org/10.1126/science.aax8591

Steffan-Dewenter I, Leschke K (2003) Effects of habitat management on vegetation and above-ground nesting bees and wasps of orchard meadows in Central Europe. Biodivers Conserv 12:1953-1968. https://doi.org/10.1023/A:1024199513365

Stevens KC, Jack CJ, Ellis JD (2019) Featured creatures: megachile sculpturalis (Smith) (Insecta: Hymenoptera: Megachilidae). Florida Department of Agriculture Publication Number EENY-733. http://entnemdept.ufl.edu/creatures/MISC/BEES/Giant_resin.html
Teh-Weisenburger JL (2017) Insect hotels: a refuge or fad? The Entomoloigst Lounge, September 18, 2017. https://entomologistlounge. wordpress.com/2017/09/18/insect-hotels-a-refuge-or-a-fad/. Accessed 1 June 2020

Theodorou P, Radzevičiūtè R, Lentendu G et al (2020) Urban areas as hotspots for bees and pollination but not a panacea for all insects. Nat Commun 11:576. https://doi.org/10.1038/ s41467-020-14496-6

Thomson DM (2016) Local bumble bee decline linked to recovery of honey bees, drought effects on floral resources. Ecol Lett 19(10):1247-1255. https://doi.org/10.1111/ele.12659

USEPA (2015) National strategy to promote the health of honey bees and other pollinators. https://obamawhitehouse.archives.gov/sites/ default/files/microsites/ostp/Pollinator\%20Health\%20Strategy\% 202015.pdf. Accessed 18 May 2020

Vanbergen AJ et al (2013) Threats to an ecosystem service: pressures on pollinators. Front Ecol Environ 11(5):251-259. https://doi.org/ $10.1890 / 120126$ 